\title{
Perspective
}

An occasional series in which contributors reflect on their careers and interests in psychiatry

\author{
Asking Questions \\ John L. Crammer
}

\section{The making of a psychiatrist}

I didn't start psychiatry until I was 33 . Since qualification I had been a science Ph.D. drop-out, an RAF medical officer, an idler on the Riviera, a medical journalist. I was a noncompetitor, without any particular ambition, who lived contentedly on little money and did not suppose it was open to me to make a lot more. I expected to stand on my own legs and go my own way, and the idea of seeking advice from others was strange; the thought that anyone might or ought to help me never entered my head.

My father was a schoolmaster who taught classics and history, and who had lost his job at a public school when he was unwise enough to write a letter supporting the Labour Party to a local paper. Ours was an arts family, but at the age of 12 I suddenly got interested in science. I was impressed by a chemistry master at my grammar school, and borrowed from him a book on the lives of the great chemists. I went on from this to borrow many books from the public library, first on the history of science and on nineteenth century chemistry, and then, for some forgotten reason, on the social insects, ants and bees. Then I moved on to experimental embryology and got very excited by the new work on the organizer, a substance of unknown nature that appeared in early embryos when they were only simple balls of cells and which induced the cells to start grouping in elongate bilateral symmetry and tucking in at one end to form the gut. This decided me to study biochemistry. Meanwhile I had a chemistry set and a microscope; I dissected a mouse and a beetle; I studied the orientation to light of freshwater shrimps from our local brook and tried to determine their colour vision; and I took my temperature every two hours through the 24 with a clinical thermometer to see if it were true that $98.4^{\circ} \mathrm{F}$ was 'normal'.

My father wanted me to be an Oxbridge don. I got into Cambridge, but I thought becoming a don was rather unlikely, and how could I earn my living as a biologist? I never thought of government or industry, or agriculture; medicine seemed the clear answer. I hated anatomy and pathology, dead meat subjects like learning the street map of Birmingham, but I enjoyed physiology and biochemistry, and did well enought to be encouraged to stay on for a Ph.D. I wanted to study protein structure, but my supervisor, Albert, had a grant to discover what it was in liver which cured pernicious anaemia, so I began on that.

At that time patients were treated by injections of a liver powder which contained peptides, pigments, carbohydrates and other gunk, and this produced a reticulocyte response and slow rise in erythrocytes. Our job was by various manoeuvres to fractionate the powder and test each fraction for activity in a patient, to see how we could separate out the active principle. Patients suitable for this test were rare, our progress minuscule. I thought the thing to do was to try to discover some unusual property in the powder, and then go for that, and only test it clinically at the end when we had somehow isolated it. I knew that copper and zinc were important in some enzymes: was a trace metal going to be the answer in the pernicious anaemia factor? So we looked for trace metals in the powder; that is, we asked a spectroscopist to burn some powder in an electric arc between carbon electrodes and examine the spectrum of the emitted light for the characteristic lines of various metals. He did this, but having no clean carbon electrodes to hand used cobalt-steel ones instead. He reported that only the lines of cobalt and iron were seen in the spectrum, presumably from the electrodes, and no other metals were present. It was left to Lester-Smith, somewhat later, to discover that cobalt was the trace metal in question, and to isolate vitamin $B_{12}$.

Meanwhile, I looked at the colour of the powder solution in ultra-violet light. This changed according to the $\mathrm{pH}$ of the solution, and I learned that it was due to tyrosine, which behaved like a kind of litmus and changed colour from acid to alkali. I wondered whether the tyrosine in proteins would change colour in the same way when titrated and discovered that in some this was only possible once the protein was denatured. This told us something new about protein structure; I contributed to this subject after all.

Albert was an excellent supervisor who took a close interest (his other student at that time was later a Nobel prizeman), and I had a happy and successful year with him-and then he left for another post, and the grant with him. What to do? I was keen to leave the academic cloister and experience the world of hospital and London, and this suited the biochemistry department. So I became a clinical student in Bloomabury. A don I knew had given me great encouragement to start in popular science journalism, and I began writing a monthly column on science for World Review and doing something similar for Penguin Books, which with my school fees paid by a scholarship and a small loan from a friend made me almost self-supporting. I enjoyed clinical work, especially medicine, but I could not stomach surgical pathology and anatomy and in consequence failed the $\mathrm{MB}$ several times and qualified on Conjoint. Another friend was just leaving as house physician at an LCC hospital, Archway (Whittington). I stepped into his shoes and took over a ward of 50 medical patients-in preNHS days, when there were no registrars or senior registrars, 
and the patients were all mine, with a consultant in the background. It was excellent experience, plenty of responsibility. I became expert at diagnosing the acute abdomen in emergencies sent up after $6 \mathrm{pm}, \mathrm{I}$ gave anaesthetics for emergency surgery at night, and anaesthetized children one afternoon a week regularly for tonsillectomy. I would have liked to specialize in medicine, but I could see it was competitive, and it meant sitting the MRCP which was not easy to pass, so I crossed that idea out. With some hesitation I went back to biochemistry, with a new subject and a new supervisor I didn't like, who left me to my own devices. It was altogether a miserable year, and I missed the clinical world. So I threw up the lab and joined the RAF as a national service medical officer.

The next two and a quarter years were very varied: in charge of sick quarters with beds, doing a bit of general practice among airmen's families, watching over industrial health in underground workshops where electroplating and paint spraying went on, teaching aviation medicine to aircrew, flying around Britain in two-seater aircraft, reading Air Ministry files to write a fragment of war history. I liked the cameraderie and support of service life, and particularly enjoyed meeting a great range of men and women who had found a niche in the RAF. Their lives and personalities were so different from any of the stereotypes I had expected. I began to think of becoming a dermatologist, until the Dean of the Institute told me I must get the MRCP first. I wondered whether I could get a job teaching physiology. In the end I decided to retire while I was young enough to enjoy it, and work later. I went down to the South of France to lodge with a French family and learn to speak the language. I mixed with potters and painters, misfits and sexual deviants, transients and locals of all kinds. It was another broadening of sympathies and deepening of knowledge of humans, which proved useful when I finally became a psychiatrist.

After a bit I was considering taking a student resident's job at the hospital at Grasse (nurses gave the anaesthetics there, and one didn't use a stethoscope but spread a serviette over the chest and put one's ear direct to that) when my anxious father sent me a newspaper advertisement for a job as assistant editor of the $B M J$. The idea of working in an office and going to the printers appealed to me, so I came back to London-and got the job. It was easy but quite interesting work, but didn't offer much creative scope, and committees and medical politics were boring. I felt I must get back to clinical practice. After two years I left the $B M J$, but for some years continued to write leaders and meetings reports for them and, to a lesser extent, also for the Lancet, as well as doing other journalism, including a short spell as medical correspondent of The Guardian. I was flattered when I left that paper and the editor said to me: 'Your stuff's all right, but you're so damn lazy'. I later thought there was a sort of truth in his last word. Meanwhile I was brushing up my clinical work, and deciding it would have to be psychiatry-least competitive of subjects, easiest exam. I was lucky enough to get an SHO job at the Maudsley: it was 1954.

Mental hospitals had always intrigued me since, years before, a social worker friend of my mother had shown me round a local asylum, and it was like visiting an interesting foreign country with strange customs. I already knew of Gjessing's work on the biochemistry of periodic catatonia and its successful treatment with thyroxine, and thought my biochemical knowledge might prove useful in psychiatric work. Of course as a medical student I had been to a few boring mental health lectures, and made optional attendances at a comic Saturday morning demonstration of the mad at a mental hospital, as well as sitting in once or twice with a psychiatrist in out-patients-in other words, I really knew nothing about psychiatry.

\section{Getting down to work}

But I had read some Jung and Freud, and the like, and I was expecting to be taught a psychodynamic rather than organic approach, and was ready to welcome this. A double disappointment awaited me. While there was certainly interesting psychodynamic teaching, it was on a different intellectual level from the rest of the teaching - a good deal of it was theological rather than scientific. It soon appeared that the great bulk of Maudsley patients were unsuitable for intensive analytical psychotherapy, but were to be treated with ECT or psychotropic drugs: 1954 was the year that chlorpromazine came in. At the same time one was made aware of the importance of relationships, of staff with staff and patients with patients, as well as the obvious one of staff with patients, and of the great importance also of understanding the attitudes and relationships outside the hospital in the society from which the patient came and to which he would return.

The Maudsley had some bad features. I didn't like the atmosphere of intense competition and overwork, nor the fact that some of the junior staff were an élite who got the best opportunities while others of us were just hacks to fill in on the work. Anyway, I was not reappointed at the end of the year, so I picked out a job as registrar at Cane Hill as about my mark, and got it. The superintendent, Dr A. Walk, was an editor of the Journal (of Mental Science). When interviewing me he said: 'Are you the man we are looking for to come on the Journal?'-and 14 years later I was.

At that time Cane Hill had about 2000 patients and was a great living museum. It was fascinating to see what one could discover in the wards, and the staff was small enough to work as one. Apart from Walk there were only two consultants and three SHMOs, a senior registrar, and two each of JHMOs and registrars. This hospital taught what the Maudsley couldn't, the management of wards and the co-ordinated running of the hospital as a whole. It was educational to have the whole medical staff meet every morning at 10 am for half an hour to discuss particular management problems and general policies. Every day I had to visit each of the five or six wards in my charge (about 200 patients) and one purpose of this was always to make sure that no door was locked except those authorized to be locked, no patient was secretly shut away, nobody was being injured without official cognisance of it, proper nursing and drug records were being kept, and ward morale was not sinking in either staff or patients. I was an inspector and guardian of rights and proper practices, as well as medico, psychologist, and a bit of a social worker too. I 
enjoyed listening to the patients talking about their past lives and interests as well as what it felt like to be ill. It was exciting to see what the new drug chlorpromazine tried in various ways could do for them.

My eye was caught in a ward for the chronically disturbed by an old man who went in and out of stupor. A friend lent me a weighing machine (there was otherwise only one in the whole hospital at that time) and I began to keep a daily diary in which at each visit I noted the mental state and weight of this old man, as well as his resting pulse and often his BP. I also kept a weight and mental record of five or six others in the same ward, some chosen for known mental variability, others for known mental constancy. In the course of 18 months I collected enough information for two papers, one on periodic psychoses, the other on weight change in psychosis and its interpretation as change in body water produced by change in neural control.

I saw an advertisement for a research fellowship in Birmingham at the University Department of Experimental Psychiatry. The pay was less than a senior registrar's but on the other hand I could continue my periodicity and body electrolyte studies, so I applied and got the job there, and went on to produce two more papers, thanks partly to the guidance of W. Mayer-Gross, who, in retirement, was also a research fellow in Birmingham.

After 18 months the head of the department left for the USA, and the money evaporated, so I had to find a job again. I went to see Denis Hill who was then on the MRC. His advice was: 'Do six years' more work and then come back to the MRC, and we may support you.' This was realistic, but not encouraging. Later I happened to meet Albert, my original research supervisor, and he arranged for me to see Aubrey Lewis. At the end of that interview Lewis said: 'You will always do research; there's no need to help you'.

I ought to have followed the advice of another senior psychiatrist and tried my luck in the USA. Instead, with a grant from the Mental Health Research Fund I went on a bit in London, experimenting with lithium, continuing on periodic illnesses, and learning how difficult it is to do research on other people's patients if the other people retain clinical responsibility. I was 41 , getting tired of temporary jobs and low pay, and no future, and I had to have my own patients if I was to do clinical research. So, with Mayer-Gross's help I applied for and got a consultant psychiatrist post at a Birmingham hospital. It was a new harsh world, and for the first time I had administrative responsibilities in the NHS.

\section{Health Service problems}

The hospital still lacked another consultant and two registrars (though these vacancies were soon filled), morale was low and the junior staff spent much of the day drinking coffee in the common room. I found an admission ward with an unsorted chaos of 60 patients, some of whom had never been examined (one man proved to have cerebral tumour). The first thing was to set up Maudsley-style history and examination for each one and to lead the juniors into doing it, the second to reorganize ward use, the third to start discharging patients who no longer needed in-patient care, using weekly conferences with social workers who came from the City Hall. Here I struck on practices very different from those I had known in London.

There was a nice old man who had had a little watch repair business in the slum centre of the city, and had refused to move out into alternative accommodation in some new distant suburb when the authorities decided to pull down and redevelop the slum. He rightly pointed out that he could not hope to continue his business on a new estate. He was a thorn in the side of the Housing Department, until they discovered he had some paranoid ideas and got him certified and admitted. I proposed to discharge him-he was certainly fit enough, and not only harmless but able to work usefully. But a social worker came to me and said: 'Frankly, it's as much as my job's worth to let that man out of hospital'. There was another much younger man who had been eight months in hospital with a depression, and meanwhile his wife had gone into another hospital with TB. The man was ready for discharge, and had been a council tenant, but because he and his wife had been away for more than six months their council house had been taken away from them (a council rule, I was told). However, the man's mother had a spare room, and would take him if only he could get a bed for it. I thought we could get one from his furniture, which must have gone into store when his house was taken back: London social workers would have made an inventory of everything so stored. Not so in Birmingham: there was no inventory, no furniture. 'It was all rubbish, so we threw it away', I was told. Another little incident: a social worker asked me to do a domiciliary visit on a girl of 18 who was at home suffering from TB. The medical officer of health wanted her certified and sent to our hospital because she refused to go into a chest hospital, which he considered necessary. Of course she had no mental symptoms. It turned out that the mother had previously had TB and the girl had nursed her at home. Now she in turn was ill she wanted similar care. and the mother was willing, so finally the $\mathrm{MOH}$ accepted this.

These were all signs of the hierarchical society of Birmingham. If you were poor you had few rights, and often expected none, or at least did not protest very much. This went on all the way up the scale. Our superintendent decided everything without consulting us either beforehand or afterwards, and was capricious in his rule. The management committee of the hospital ignored the doctors and the Regional Authority seemed to ignore everyone else. This was a cause of the low morale in our hospital, and regionally the cause of the occasional emotional explosion which made headlines and resulted in public inquiries with QCs and printed reports. Every official aim seemed to be to stifle criticism, however constructive, clamp down on those below and compel them, not lead them. to work in a certain way.

Perhaps this was why such NHS committees to discuss policy as I attended continually drew up plans but nothing ever happened afterwards. and why I became so unpopular with colleagues when I pointed this out. I remember a postgraduate training committee, before the days of any university department of psychiatry, drawing up in two or three successive years a grandiose lecture course in which every consultant in the region had his two or three special lectures- 
but nothing was ever actually held. I went away, asked two chaps to teach psychology and neuroanatomy every week and the pathology department to put some brains in pickle for us. and in no time we had about 20 registrars from different hospitals coming regularly to prepare for the London Conjoint DPM. We started weekly case conferences and scientific talks, at which, until he died, Mayer-Gross would sometimes come, and our general activity was such that a consultant colleague protested to me: 'We must remember we are only a provincial mental hospital'.

I was lucky to be able to escape from a city run by the Mafia, so it seemed, to a country area where democratic equality and the pursuit of good practices by discussion were the rule. The Oxford regional board was a pleasant, approachable and helpful body to work for, our hospital base well organized, and the medical staff in harmony under a medical director with a gift for management (though narrower responsibilities than a superintendent). The hospital secretary, for the years before the general hospital took us over, was a youngish man who still retained the outlook of unit adjutant from his army days. That meant that he was prepared to use the maximum of autonomy quite selflessly to promote the good of his outfit, without much regard for senior officers. When I wanted a laboratory assistant for my research he was quite prepared to find the salary by appointing him 'assistant pig farm manager', an established post long vacant since the closure of the farm years before. When the hospital had a little spare cash near the end of the financial year he was happy for me to buy a liquid scintillation counter or other apparatus, and the result later was papers on imipramine metabolism in Psychopharmacologia.

The one handicap to first-class work was the lack of nurses. The establishment, if there was one, had been set too low, at least for the work being done in 1964. Two or three of us started coming in around midnight to see how the hospital was running then, and discovered some wards with no night nurse, the patients just locked in by themselves until morning. A night patrol might pass through some time in the night-and one time caught the beginnings of a fire. Another time a schizophrenic young man was found dead in the morning. hanging in a lavatory: the inquest hushed it up. There began to be trouble by day also; a suicide in the morning in an admission ward where lack of staff was contributory, an escape from another ward, dangerous situations in a third, all because one nurse could not do everything.

I started a detailed analysis of how many nurses, male and female, of all the different grades there were, from pupil and student nurses, nursing assistants, state-enrolled and stateregistered nurses, mental and doubly trained nurses, charge nurses, nursing officers, and even ward orderlies. I examined the number on each shift, and the distribution by wards. I counted up the sick leaves, study leaves, annual leaves, and the unfilled vacancies on the staff (we always ran a little below establishment for fear of overspending on the year).

What emerged first and foremost was that the bulk of the staff was neglecting psychiatric patients to care for old people. getting them dressed, feeding them. putting them to bed, turning them over. and each nursing shift had to have at least two able-bodied people working together to lift one patient. The wards were actually overflowing with geriatic cases, extra beds were up for them, they spilled over into the corridors, they were beginning to occupy beds in the acute admission wards and were difficult to discharge again. So I started an analysis of all the patients over 65 in the hospital. It became clear there was a core population which had been in some while and was long-lived. It consisted of three or four diagnostic types. There were people who were really chronically sick-the aftermath of severe accidental brain damage, or of meningo-encephalitis, or advanced multiple sclerosis. There were people with marked histrionic-cum-hypochondriacal personalities whom everyone found intolerable to live with. There were people with multiple difficulties: elderly schizophrenics who were also blind, elderly manic depressives who were diabetic with one leg amputated for gangrene, and so on. The demented and senile were only a fraction of the total, and many of them were there because they had no surviving relative of any sort, and were unacceptable in an old people's home.

I extended my study of nursing staff, and to some extent also of geriatric cases, to another Oxford area hospital of about the same size that seemed to be doing much better. They were said to have the same size of staff. So they did, in pure numbers, but they had a greater proportion of fullytrained staff, a greater proportion of full-timers rather than 'whole-time equivalents', and they were more successful at recruitment (perhaps for geographical reasons), and replaced lost staff more quickly. It also became clear that the two hospitals did not have identical work: a hostel ward of $\mathbf{4 0}$ mobile long-stay patients may manage with one part-time nurse, an acute admission ward of 20 beds may need three nurses per shift with at least one fully trained and experienced. It depends on the severity of illness and the rapidity of discharges. If you are going to consider hospital staffing seriously, instead of simply fudging to fight off demands for more money or people, you have to begin by splitting the hospital into zones of activity, and expressing separately for each the amount of work to be done and the number of people available to do it, and even the degree of training needed for it. Administrators did not do that-they used patient:nurse ratios globally for the whole hospital, or counted as nurses all the living who appeared on the staff roll. They confused themselves and misled others. But this has been a general characteristic of NHS statistics.

Does one still make an annual return to the DHSS on the number of patients resident in the hospital at midnight on 31 December? Some people considered this meant only patients actually sleeping in that night, others thought it included those on leave but still on the books. Either way, the total was used administratively as a guide to the work of the hospital, thereby under-estimating it, because one tries to discharge patients in time for Christmas and not admit new ones until after 1 January, out of consideration for staff as well as patients. I remember the hospital secretary putting his head round the door and saying: 'I've just had a call from the DHSS asking how many alcoholics we treated last year: what shall I say?' Except for special research projects, hospitals do not keep 
registers by diagnosis (the DHSS ought to know that, since they do not require it to be done), so of course we could not answer. 'Well. I'll tell them my age', said the secretary, and vanished. Some time later there duly appeared in Hansard, copied in The Times, Lancet, etc; 'In answer to a parliamentary question on 13 March, the Secretary of State said that xxxx alcoholics had been treated in NHS hospitals last year'-we knew that was a piece of rubbish over which many people had wasted time and money. If I were a different sort of chap I would have started a campaign to replace phoney figures with genuine data, and to press administrators to use them in taking rational decisions instead of preferring, as they do, to talk things over in ignorance and then decide by the light of nature. I think the NHS would at once become more efficient.

But who do you approach in such a campaign? Twenty-four years as a consultant in the NHS showed me over and over again that it is often very difficult to find out who (if anyone) is in charge, who is actually responsible for this or that category of decision in the NHS and which way the chain of responsibility runs. If you can identify the responsible person, you can write to them or speak with them. In the NHS it is more like writing to Santa Claus.

A ship has a captain, an orchestra has a conductor, a school has a headmaster, an army has officers and generals ... What is so unique about hospitals that they alone should function, with all their many different activities and many members of different professions together, without a head, an organizer, a responsible individual? Who will keep harmony, who will steer a course to avoid rocks and sandbanks, who will maintain order? No wonder there is waste, sinking morale, sad mishandling of patients, dirty worn-out wards and equipment. Without efficient management, the NHS is slowly choking itself to death.

The analysis I made of nursing and patient numbers used data already available, but it was no one's business to bring them together and analyse them. The hospital was running badly, and we individually could see some of the signs of this, but it was no one's business to see the full overall picture. The cure involved splitting off geriatric services and setting limits to their work; and also a complete reorganization of nursing services, which was very painful. Had there been an overall manager, it is unlikely that things would have gone wrong like this in the first place, or taken so long to correct. It was painful for the staff, and inhumane, even lethal, for some of the patients. We did not need an old-style superintendent, but we did need one person as responsible head.

Consultants think of research as something technical, involving apparatus, statistical calculation, grants, and leading to papers or degrees. But it is something much simpler: asking questions. Now that I look back I think that analysing the nurse distribution and the hospital's work was quite as much research as giving radioactive imipramine to rats, and of much more immediate use.

\section{Looking back}

'You will always do research', said Aubrey Lewis, and, on and off, this proved to be true. But looking back at all my quarter-finished projects, unpublished data, papers needing revision and shoved in a drawer, I see I was too much a loner, too fluctuating, too little the scholar, so in the end, apart from a few crumbs, I produced nothing. I needed someone to control my tendency to wander off on new projects, to carry me over periods of boredom or despondency, to encourage perseverance and contact with others. Nurturing potential research workers is a difficult art, akin to psychotherapy, but I fear that very few of us seniors see it like that. We raise difficulties all the time over the quality of projects, standards of the applicant's hospital, the need for money, and only help when the young man or woman shows great persistence. We do not often do positive things-repeated encouragement or spontaneous advice, helping the young worker to link up with more experienced groups and get specialized collaboration, and enquiring into the personal difficulties holding things up. Research is often seen as a luxury, or privilege, or some kind of hobby. Some of it, however, has a direct impact on everyday life. The atmosphere of enquiry improves the standard of clinical practice of everyone around, not just the researcher; the results of enquiry sometimes have an immediate effect on the organization of the week's clinical work. More generally, research brings commercial and international benefits to the whole community, as well as new health prospects. I enjoyed my life, I have no complaints, but I think society might have got more out of me if someone had turned me from an amateur into a professional.

\section{Interdisciplinary Working Party Discussion Document; A Guide to Confidentiality in Relation to Mental Health}

This discussion document, which has been approved by Council as a discussion document, was produced by a Working Party representing a range of disciplines and interests to try to produce a common understanding of the issue of confidentiality between clients and professionals, with the emphasis on the health and social services, and in particular, mental health services.

The discussion document attempts to examine the topic of confidentiality in relation to the various settings in which it has to operate and to state the principles and codes of practice that apply. Council agreed at its meeting in June that it provided a useful contribution to the continuing debate on confidentiality. Whilst it could not be seen as a document reflecting College policy, it was considered that it might be useful to the membership as a discussion document. Any member wishing to obtain a copy should write to: The Secretary, The Royal College of Psychiatrists, 17 Belgrave Square, London SW1X 8PG. Copies will cost $£ 1.50$ (postage and packing included) and cheques should be made payable to the Royal College of Psychatrists.

(For details about 'Confidentiality and Forensic Psychiatry'-see page 201). 